\title{
UMA TAREFA PARA MAIS DE UM SÉCULO: SCHILLER E OS POTENCIAIS FORMATIVOS DA EDUCAÇÃO ESTÉTICA ${ }^{1}$
}

\author{
VIVIAN BARONI ${ }^{2}$ \\ https://orcid.org/0000-0002-1280-1388 \\ ANGELO VITÓRIO CENCI ${ }^{3}$ \\ https://orcid.org/0000-0003-0541-2197
}

\begin{abstract}
RESUMO: Escritas no final do século XVIII, na obra $A$ educação estética do homem numa série de cartas, Schiller ultrapassa a discussão acerca da arte ao identificar a necessidade urgente de uma educação estética enquanto cura para os males trazidos pela modernidade. No presente artigo, procuramos reconstruir a concepção formativa que embasa a discussão presente nas Cartas, procurando demonstrar a atualidade de suas premissas educacionais. Para tanto, estudamos as concepções históricas que influenciaram a redação das Cartas, assim como os conceitos centrais que embasam a sua concepção de educação estética. Também analisamos o papel da educação estética enquanto contraponto da fragmentação e no questionamento acerca do lugar da sensibilidade na formação. Com tal estudo, esperamos evidenciar a importância da educação estética schilleriana no contexto atual ao recuperar aspectos críticos e emancipatórios da arte enquanto formação humana e projeção de uma racionalidade ampliada.
\end{abstract}

Palavras-chave: Educação estética, Formação, Schiller.

\section{A TASK FOR MORE THAN A CENTURY: SCHILLER AND THE FORMATIVE POTENTIALS OF AESTHETIC EDUCATION}

\begin{abstract}
Written in the late eighteenth century, in the work Letters upon the aesthetic education of man, Schiller goes beyond the discussion of art by identifying the urgent need for aesthetic education as a cure for the ills brought by modernity. In this article, we seek to reconstruct the formative conception that supports the discussion present in the Letters, seeking to demonstrate the relevance of its educational premises. For that, we studied the historical conceptions that influenced the writing of the Letters, as well as the central concepts that base their conception of aesthetic education. We also analyzed the role of aesthetic education as a counterpoint to fragmentation and in questioning the place of sensitivity in training. With such a study, we hope to highlight the importance of Schillerian aesthetic

\footnotetext{
${ }^{1}$ Financiamento: PROSUC/CAPES; PDSE/CAPES

${ }^{2}$ Universidade de Passo Fundo (UPF). Passo Fundo, RS, Brasil. <vivianbaroni@hotmail.com>

${ }^{3}$ Universidade de Passo Fundo (UPF). Passo Fundo, RS, Brasil. Professor no Programa de Pós-Graduação em

Educação e no curso de Filosofia.< angelovcenci@gmail.com >
} 
education in the current context by recovering critical and emancipatory aspects of art as human formation and projection of an expanded rationality.

Keywords: Aesthetic education, Formation, Schiller.

\section{UNA TAREA ADEMÁS DE UN SIGLO: SCHILLER Y LOS POTENCIALES FORMATIVOS DE LA EDUCACIÓN ESTÉTICA}

RESÚMEN: Escrito a finales del siglo XVIII, en la obra La educación estética del hombre en una serie de cartas, Schiller va más allá de la discusión del arte al identificar la necesidad urgente de la educación estética como una cura para los males traídos por la modernidad. En este artículo, buscamos reconstruir la concepción formativa que apoya la discusión presente en las Cartas, buscando demostrar la relevancia de sus premisas educativas. Para ello, estudiamos las concepciones históricas que influyeron en la redacción de las Cartas, así como los conceptos centrales que basan su concepción de la educación estética. También analizamos el papel de la educación estética como contrapunto a la fragmentación y al cuestionar el lugar de la sensibilidad en el entrenamiento. Con tal estudio, esperamos resaltar la importancia de la educación estética schilleriana en el contexto actual mediante la recuperación de aspectos críticos y emancipatorios del arte como la formación humana y la proyección de una racionalidad expandida.

Palabras clave: Educación estética, Formación, Schiller. 


\section{INTRODUÇÃO}

Escritas à luz da estética kantiana, as obras de Schiller guardam em si uma relação estreita com a ideia de formação, contudo, é na obra $A$ educação estética do homem numa série de cartas (2002) o lugar onde o autor reúne uma reflexão mais sistemática sobre a temática formativa. Redigidas entre 1794 e 1795 em forma de epístolas, Schiller comunica a seu mecenas, o Príncipe von Augustenburg, os avanços que havia feito e que esperava realizar no âmbito da estética. Embora Schiller mantenha ainda a ideia de desenvolver uma analítica do belo, seguindo as teses já expostas em Kallias (1999), tais considerações prévias levam-no em outra direção, pois lhe mostram a urgência de uma educação estética da humanidade. Será esse o tema em que se ordenam as reflexões sobre a beleza que o autor desenvolverá em suas cartas ao Príncipe, as mesmas que, após corrigidas e ampliadas, acabariam por converter-se no seu mais célebre ensaio.

Para Schiller, os problemas que acometem a sociedade derivam da natureza cindida do ser humano, na qual a separação entre impulso sensível e impulso formal ocasiona desequilíbrios que levam a extremos, gerando sujeitos fragmentados e heterônomos, pois são incapazes de desenvolver a totalidade de suas capacidades. A harmonia entre os dois impulsos somente é alcançada pela via da educação estética, a mesma em que se manifesta o impulso lúdico enquanto jogo entre as capacidades sensíveis e racionais. Nestes termos, a superação da cisão interior por meio do impulso lúdico leva à educação do homem como um todo, em harmonia consigo mesmo e com o mundo, ou seja, à Bildung.

Ainda que distanciadas em termos temporais, não há como negar a ingente atualidade das Cartas, sobretudo quando observamos que os problemas aventados por Schiller, como a fragmentação, continuam presentes em nossa época. Neste sentido, procuramos resgatar a importância da educação estética de Schiller para pensar a educação na contemporaneidade. Para tanto, desenvolveremos o presente artigo em três partes. Na primeira, estudamos alguns dos fatores que levaram Schiller a redigir as Cartas, como a Revolução Francesa e as consequências que esse movimento acarretou. Também veremos como Schiller trata da relação entre Estado, política e estética nas Cartas. Na segunda parte, iremos trabalhar com os conceitos de impulso formal, impulso sensível e impulso lúdico, assim como com a concepção de educação estética schilleriana. Na terceira e última seção, vamos problematizar a atualidade da educação estética schilleriana, procurando repensar o lugar da sensibilidade no processo formativo.

\section{DO ESTÉTICO AO POLÍTICO}

Durante o período de 1791 a 1795, Schiller redigiu praticamente todos os seus escritos estéticos. Neles, é possível observar a expressão filosófica tanto de sua autoconsciência enquanto artista, como a sua atitude frente à modernidade em surgimento, que aparece na tomada de posição diante da obra de Kant, da Aufklärung e dos rumos da Revolução Francesa. Desses textos, ressalta-se o seu mais célebre ensaio, A educação estética do homem numa série de cartas, na qual Schiller busca ampliar a capacidade libertadora do belo ao âmbito da política e da sociedade. As Cartas são redigidas não a um especialista em estética, mas a um homem de Estado, que lhe exige a máxima clareza e simplicidade expositivas, e obrigam-lhe a realizar uma série de considerações sobre o belo e o gosto quanto à sua influência sobre o sujeitoe a sociedade.

Nos termos em que a hermenêutica exige uma compreensão que considera o panorama histórico-social no qual se insere o texto a fim de compreendermos as exigências explicitadas nas Cartas, precisamos também conhecer o panorama da época que vai apresentar um Schiller profundamente ligado às questões postas por seu tempo. O século XVIII já fazia sentir por toda a Europa os ventos da mudança que partia da França enquanto centro dos novos ideais: o Iluminismo. As tensões políticas cresciam influenciando pensadores como Rousseau, Voltaire e Montesquieu, que propagavam o ideal de reforma da sociedade através da razão. O interesse do povo pela libertação da religião e da monarquia colocava a razão como única força capaz de garantir a liberdade e os direitos do homem. Ainda que a raiz do movimento venha da França, esses ideais espalham-se por toda a Europa, de maneira que, na Alemanha, o movimento, agora denominado Aufklärung, refletia o clima de 
esperança que acreditava na potencialidade do indivíduo em livrar-se de seu estado de menoridade, criando condições através do entendimento para alcançar a liberdade social.

Schiller deixa-se influenciar por esse movimento progressista vendo, naquela onda de mudança que proclama os ideais da razão, também uma onda de esperança para uma sociedade apática. A razão orientando os ideais da igualdade e liberdade parecia prognosticar uma nova fase na história da humanidade. Apesar disso, a Revolução Francesa de 1789 e as consequências nefastas engendradas por ela culminam numa reviravolta histórica que vai afetar diretamente o pensamento alemão. A violência em que vai resultar traz consigo o peso da desilusão, assim como um desânimo incomensurável que se espalha por toda a Europa. Na Alemanha, nasce uma necessidade de não apenas expor as críticas em relação à revolução, mas também dá-se relevo à tarefa urgente de encontrar uma solução para essa barbárie que acabava de instalar-se no seio da razão. Nesse mote, pensadores como Goethe e Eckerman escrevem respostas a essa fase histórica. Contudo, será Schiller - e esse é o ponto mais importante - o primeiro a propor uma resposta à violência através de um projeto de educação estética. Schiller vale-se de conceitos kantianos para ser o primeiro a colocar a crítica da modernidade como uma crítica estética. A estética, neste contexto, está intimamente ligada a uma dimensão política e histórica: um projeto de crítica da cultura moderna .

As nove primeiras cartas caracterizam-se essencialmente pela crítica à racionalidade ilustrada, cujo ponto de partida é o pensamento de Rousseau. Pode-se ver, nelas, o retrato de um Schiller desiludido com o Iluminismo, com a ênfase extremada dada à razão teórica que, mais tarde, acabou por derivar na violência do Terror. Escritas sob o impacto das consequências regressivas da Revolução Francesa, da brutalidade pela qual Schiller viu inscrita na face da sociedade o espectro do Estado de natureza, as Cartas buscam refletir as exigências universais da revolução burguesa com e contra a Revolução Francesa (BARBOSA, 2004, p. 14). Embora o teor seja de crítica, esta não é tomada em seu viés conservador, pois a sua preocupação fundamental é com a falta das condições subjetivas fundamentais imprescindíveis ao estabelecimento de um Estado racional. É daí que se pode observar o caráter eminentemente pedagógico das Cartas.

É importante notar que o fracasso da Revolução Francesa teve um peso central na redação das Cartas, pois quando parecia a Schiller que o Estado natural seria suplantado pelo Estado moral, quando a razão colocava-se à frente de um projeto de sociedade orientada para a liberdade, a humanidade infelizmente mostrou-se despreparada para tal feito. Quais foram as causas desse fracasso? Schiller vai procurar encontrar essa resposta nas Cartas, mostrando que a ênfase ora na natureza formal ora na natureza sensível não faz mais que acentuar a natureza cindida do ser humano como um ser incompleto e finito. Ambas as legislações, razão e sensibilidade, não são capazes de sozinhas gerar projetos emancipatórias porque são limitadas. Pela beleza, veremos mais adiante, Schiller encontra o caminho que as faz andar juntas em mútua interdependência, para, através de uma educação estética, alcançar a liberdade. De acordo com Süssekind (2011a, p. 15), o filósofo faz confluir nas Cartas as questões políticas ligadas à Revolução Francesa com uma teoria filosófica da arte. Partindo do diagnóstico da cisão e, portanto, da duplicidade da natureza humana, Schiller propõe que a formação, para evitar esse duplo descaminho que impede a realização da liberdade, deva passar pela arte e pela beleza enquanto instâncias capazes de harmonizar a dualidade do homem. Nesses termos (e aqui não há como não fazer uma analogia com o Schiller médico), a educação apresenta-se como um remédio, uma cura para a perversão e selvageria da modernidade. Como ressalta Barbosa (2014, p. 147), nas Cartas, a formação de uma cultura estética é colocada por Schiller como a única terapia eficaz frente ao diagnóstico da modernidade.

Para ler as Cartas, Duflo (1999, p. 66) destaca que é preciso ter em mente que Schiller não parte de uma solução, mas de um problema, e não o faz por meio de uma exposição dogmática, mas ancora a argumentação em um campo herdado diretamente de Kant. Duflo sugere que poderíamos ler a primeira parte (Cartas I a IX) como tentando dar conta do problema da divisão antropológica por meio de uma antropologia pragmática de apelo político e histórico. A segunda parte (Cartas X a XVI) deixa a antropologia pragmática para buscar, na antropologia pura, as origens dessa divisão e encontra, no belo e no jogo, a possível via para a solução do problema. A terceira e última parte (Cartas XVII a XXVII) continua e aprofunda a análise do problema e da sua solução. 
De início, e dando o tom da discussão que se seguirá, Schiller chama a atenção para a necessidade de pensar a arte em uma época em que tudo se volta para o político. Enquanto os acontecimentos pulsam na direção do concreto, do eminente cotidiano, na qual "a utilidade é o grande ídolo do tempo", a arte parece desaparecer e os seus limites estreitam-se na medida em que a ciência amplia os seus. A Revolução Francesa havia aberto um debate em toda a Europa sobre as questões políticas, mantendo ocupados com essa temática os pensadores daquele tempo. Neste sentido, ocuparse com o tema estético em um momento em que a investigação filosófica é solicitada a ocupar-se da ideia de liberdade política não parece "uma reprovável indiferença em relação ao bem da sociedade?” A resposta de Schiller consiste em sustentar que, ao contrário do que parece, a reflexão sobre a estética é justamente a chave para abordar os problemas políticos:

Resisto a essa amável tentação deixando que a beleza preceda a liberdade e penso poder não apenas desculpá-lo mediante minha inclinação, mas justifica-lo mediante princípios. Espero convencer-vos de que esta matéria é menos estranha à necessidade que ao gosto de nosso tempo, e mostrarei que para resolver na experiência o problema político é necessário caminhar através do estético, pois é pela beleza que se vai à liberdade (SCHILLER, 2002, p. 22).

Para o autor, o Estado é inicialmente uma obra da necessidade natural, visto que os homens agrupam-se primeiro sob leis naturais. Porém, conforme a sua disposição racional superior, é preciso transformá-lo em um Estado moral, começado do zero como se fora fruto de um contrato livremente assumido, cujo fim seria o respeito da dignidade e da liberdade humana. Com efeito, a transição do puro Estado natural ao perfeito Estado moral não é simples nem fácil, já que, neste processo, não é possível prescindir em momento algum do Estado, ao mesmo tempo em que é necessário suprimir a legislação natural para fazer surgir a moral. Expresso em outros termos, a passagem da sensibilidade para a razão seria obra, em Kant (1995), da dimensão estética da autonomia presente na faculdade de julgar. A tarefa de Schiller será, portanto, seguir a senda já aberta pelo filósofo de Königsberg, colocando o estético como a mediação que torna realidade a transição entre razão e sensibilidade.

Para Schiller, a liberdade que aparecia como valor orientador da Revolução Francesa era uma farsa que defendia e proclamava um conceito que não compreendia. A verdadeira liberdade humana e a sua aprendizagem viriam apenas da estética, pois qual não é a "maior de todas as obras de arte senão a construção de uma verdadeira liberdade política?" (SCHILLER, 2002, p. 21). O rumo tomado pelo progresso parecia não resultar em favor da arte, afastando-a ainda do Ideal . A arte deve elevar-se para além da privação, pois a arte é filha da liberdade, e vice-versa, e quer ser legislada pelas leis do espírito, não pela privação da matéria. Esse impeditivo é encontrado no caráter da época, que Schiller caracteriza como vergado sob o jugo da privação e que encontra, na utilidade, o grande símbolo do seu tempo:

Nesta balança grosseira, o mérito espiritual da arte nada pesa, e ela, roubada de todo o estímulo, desaparece no ruidoso mercado do século. Até o espírito da investigação filosófica arranca, uma a uma, as províncias da imaginação, e as fronteiras da arte vão se estreitando à medida em que a ciência amplia as suas (SCHILLER, 2002, p. 22).

Conforme Habermas (1993, p. 64), da mesma maneira que o espírito dos negócios automatiza-se na esfera da sociedade, também no reino do espírito automatiza-se o espírito especulativo. Desse modo, desenvolvem-se, na filosofia e na sociedade, duas legislações contrárias em aberta oposição entre sensibilidade e entendimento que impingem aos sujeitos uma dupla coerção: a coerção física da natureza e a coerção moral da liberdade. Agindo segundo esses princípios, o Estado natural dinâmico e o Estado racional ético batem de frente e só convergem sob o efeito da repressão do espírito comunitário. Daí podemos deduzir, acompanhando Habermas, que a realização da razão aparece em Schiller como a ressureição do destruído sentido comunitário, que, por sua vez, não pode nascer unicamente da natureza ou da sociedade, mas apenas como um processo de formação que coloque fim à disputa dessas duas legislações.

Presente em grande parte da obra schilleriana está a ideia de que a mais alta meta da humanidade é alcançar um Estado perfeito em que a vontade individual encontre-se em harmonia com 
a vontade expressa nas leis. Em outras palavras, é preciso que a liberdade do indivíduo apareça como a única lei. Para Schiller (2002, p. 28), todo o indivíduo traz em si, enquanto destinação e disposição, "o homem ideal e puro" que encerra a possibilidade de um Estado moral perfeito. Para realizar o estado moral não há, por sua vez, outro caminho senão enobrecer ao homem temporal e individual, e convertê-lo em homem ideal e universal. Porém, isso pressupõe que o homem ideal não deva triunfar às expensas do temporal, mas que, desde o reconhecimento de sua superioridade, seja capaz de entrar em harmonia com ele. Aqui, Schiller deixa claro que não basta apenas seguir as exigências da razão, incapaz de aceitar condição alguma por parte do mundo sensível, mas há que se levar em conta um conceito de natureza humana compreendida como um todo sensível-racional:

É certo que na avaliação moral unilateral esta diferença desaparece; pois a razão se satisfaz apenas se sua lei valha incondicionalmente; na avaliação antropológica plena, porém, quando o conteúdo conta ao lado da forma e também o sentimento vivo tem a sua voz, ela será considerada tanto mais (SCHILLER, 2002, p. 28).

Para Schiller, o desequilíbrio e a desarmonia no indivíduo impedem o alcance do Estado moral. Dirigindo uma dura crítica ao espírito da Ilustração, o filósofo procura mostrar que a unilateralidade com que o desenvolvimento histórico tratou do entendimento em prejuízo da sensibilidade formou uma senda que impede não somente o desenvolvimento do ser humano como indivíduo, mas também o progresso da sociedade como um todo. Aquele equilíbrio entre razão e fantasia que desfrutavam os antigos gregos rompeu-se na mesma medida em que o entendimento e a abstração ampliavam o seu campo e reduziam, ao mesmo tempo, o da imaginação. Assim como as ciências dividiam seus objetos de pesquisa, a sociedade também se tornou mais complexa, especializando os seus ofícios e deixando as marcas desse processo nos homens.

A fragmentação, conforme Schiller, passa a ser o signo do progresso e dá o tom de seu desenvolvimento: "eternamente acorrentado a um pequeno fragmento do todo, o homem só pode formar-se enquanto fragmento" (2002, p. 36). O avanço no conhecimento e a acumulação de experiência tinham decerto que produzir essa fragmentação de um jeito ou de outro, e aquele feliz equilíbrio entre sensibilidade e razão precisava romper-se para o necessário progresso da cultura. Tal situação não pode continuar se desejasse, de fato, alcançar o Estado moral: é preciso superar a cisão interior do sujeito para que a sua natureza se desenvolva o suficiente para ser, ela mesma, capaz de assegurar realidade à criação política da razão.

Esta é, segundo Schiller, "tarefa para mais de um século", já que enquanto não se tenha restabelecido o equilíbrio no interior do homem, tampouco poderá ser recuperada a harmonia entre Estado e indivíduo. E recuperar a harmonia da natureza humana não deixa de ser o mesmo que enobrecer o caráter da humanidade, que passa obrigatoriamente pela educação da sensibilidade, que, para Schiller, "é a necessidade mais premente da época", não apenas porque ela vem a ser um meio de tornar o conhecimento eficaz para a vida, mas também porque desperta para a própria melhora do conhecimento. E, na medida em que o Estado não pode assumir essa função, justamente por ser reflexo e fonte dos males que pretende corrigir, Schiller busca, na arte, a possibilidade de romper como esse círculo que liga uma constituição política degenerada com uma humanidade imperfeita.

Schiller acredita que a verdadeira arte se eleva sobre o mundano para o ideal e plasma, através de suas criações sensíveis, os modelos universais das coisas. A arte depura a sensibilidade e oferece à razão, que, por si só, não quer nada com o temporal, um âmbito de formas eternas nas quais pode aplicar-se, infundindo ao indivíduo a harmonia que o permite mover-se através das vicissitudes de sua época sem renunciar a ela, ao mesmo tempo em que não se submete aos seus ditados (GARCÍA, 2000, p. 311). Dessa maneira, ao ser educado pela beleza o ser humano é capaz de aperfeiçoar o seu juízo ao ponto de transbordar para o âmbito do cotidiano a qualidade virtuosa de sua índole na medida em que aprende a envolver o frívolo e o grosseiro com "formas nobres, grandes e cheias de espírito [...] com os símbolos da excelência até que a aparência supere a realidade e a arte a natureza" (SCHILLER, 2002, p. 52).

Procurando qualificar o debate em torno do belo com vistas às críticas por parte dos que o tomam como mero conceito empírico, Schiller busca um conceito racional de beleza e o faz colocando-a como condição necessária do equilíbrio interno da natureza humana. Para tanto, Schiller 
deduz o conceito de beleza a partir de um conceito puro de humanidade, ou seja, coloca, como qualidade do belo, a capacidade de unificar as duas faculdades opostas da natureza humana: razão e sensibilidade. Conforme García (2000, p. 311), Schiller leva a um plano antropológico e político o que, por meio de uma perspectiva técnica, havia tentado alcançar já em Kallias ${ }^{4}$ : a ideia de que a beleza surge da harmônica reconciliação entre razão e sensibilidade. Dessa maneira, a beleza aparece como chave para restabelecer a harmonia no homem do qual depende o estabelecimento do Estado moral.

Em uma análise estética que tende eminentemente ao político, Schiller procura mostrar que é somente através de uma transformação da subjetividade individual que se pode pensar a transformação mais ampla da sociedade. Partindo do princípio de que a natureza humana é essencialmente dicotômica e cindida, e que a perfeição é um estado atingido na "unidade duradoura que permanece eternamente a mesma nas marés da modificação" (2002, p. 61), o homem só pode desabrochar quando se encontra em estado de equilíbrio. Schiller tenta mostrar que, ao contrário das leituras dos rigoristas estéticos que ignoram a natureza mista do ser humano, é preciso considerar razão e sensibilidade como duas forças potentes e antagônicas. Sendo assim, permanece inútil a tarefa de querer elevar moralmente o indivíduo sem, ao mesmo tempo, cultivar a sua sensibilidade.

\section{A TEORIA DOS IMPULSOS DE SCHILLER}

O diagnóstico schilleriano da modernidade vai, neste sentido, identificar um duplo descaminho, no qual o indivíduo ora é vítima da rudeza e tende para a selvageria, ora é vítima da perversão e tende à barbárie. Em outros termos, a ênfase excessiva na cultura teórica e na racionalidade, em acordo com o projeto iluminista, tenderia a tornar o homem refinado insensível, da mesma maneira que um homem não educado vai resultar em um sujeito inculto e escravo de seus impulsos. Trata-se de dois estados da natureza humana que são identificados pelo filósofo à semelhança da antropologia kantiana: parte racional ou moral e parte natural ou sensível.

Schiller defende que razão e sensibilidade introduzem em nossa natureza dois impulsos radicalmente antagônicos que denomina respectivamente como impulso sensível e formal. O primeiro corresponde ao nosso estado físico e preocupa-se em submeter o ser humano ao tempo e à matéria através da sensação. O âmbito desse impulso estende-se até onde o sujeito é finito, e embora seja ele quem desperta e desdobra as disposições da humanidade, é também ele que torna impossível a sua perfeição: "com ligas indestrutíveis, acorrenta ao mundo sensível o espírito que se empenha pelo mais alto, e faz voltar aos limites do presente a abstração que marcha livremente para o infinito" (SCHILLER, 1990, p. 64).

O segundo impulso, chamado de formal, tem a sua origem na natureza racional ou absoluta do ser humano e é marcado pela imutabilidade, unidade e permanência. Enquanto o primeiro impulso constitui-se pela casualidade, o segundo tem por finalidade fornecer as leis: leis para os juízos no que se refere aos conhecimentos e para a vontade no que se refere às ações. Enquanto suprime o tempo e eleva à universalidade a totalidade dos homens, o impulso formal suprime as limitações e alça o homem a uma "unidade de ideias" que compreende em si todo o reino dos fenômenos. Esse impulso independe do tempo: decide para sempre e eternamente o que decide para agora, compreendendo toda a sequência do tempo.

Podemos afirmar que o sentimento, relacionado ao primeiro impulso, só pode dizer algo que é verdadeiro para determinado sujeito em determinado momento; por sua vez, o pensamento, ligado ao impulso formal, decide eternamente a validade de sua afirmação. Apesar disso, como já discutimos anteriormente, o homem não pode ser apenas forma e o sensível faz-se necessário em todos os momentos. Schiller argumenta que ainda que se trate de impulsos divergentes, eles não são opostos por natureza, e quando aparentam sê-lo é porque transgrediram um a esfera do outro, ocasionando o desequilíbrio. Nesse caso, é preciso atentar para o fato de que é tarefa da cultura assegurar igual justiça aos dois, e não afirmar um em detrimento do outro. Em outras palavras, à cultura cabe dupla tarefa:

\footnotetext{
${ }^{4}$ Escrito durante 1792-1793, o problema principal levantado por Schiller nesta obra era estabelecer com e contra Kant um critério objetivo para o belo. O texto Kallias tem por objetivo conciliar o empírico e o a priori em um princípio objetivo do gosto a partir da natureza da razão.
} 
resguardar a sensibilidade das intervenções da liberdade formal, ao mesmo tempo em que deve defender a personalidade contra o poder da sensibilidade, incumbência levada a cabo, respectivamente, pelo cultivo da faculdade sensível e formal. Logo, na medida em que a natureza dos dois instintos é assegurada pela influência que cada um exerce sobre seu oposto, para Schiller, eles existem em estado de ação recíproca, em uma dinâmica em que "cada um ao mesmo tempo funda e limita o outro" (SCHILLER, 2002, p. 73).

Partindo desse princípio, Schiller vai afirmar que, através do desenvolvimento cultural do ser humano, o cultivo da faculdade sensível e da faculdade formal objetivaria a realização desse ideal duplo. Esse cultivo é levado adiante através de duas etapas: "primeiro: proporcionar à faculdade receptiva os mais multifacetados contatos com o mundo e levar ao máximo a passividade do sentimento; segundo: conquistar para a faculdade determinante a máxima independência com relação à receptiva e ativar ao extremo a atividade da razão" (SCHILLER, 2002, p. 69). A convergência dessas duas realizações é pensada como um ideal de unidade, ou seja, a plenitude da existência humana ocorreria na medida em que o homem consegue tomar para si o mundo sem perder-se nele, sendo capaz de submeter à razão a multiplicidade dos fenômenos. Logo, a possibilidade de um terceiro impulso vai estar diretamente ligada a essa convergência entre impulso formal e sensível, situação que é pensada por Schiller como ideal da cultura humana.

Ora, se cada um desses impulsos é capaz de atuar sobre o outro, moderando-o ao mesmo tempo que o torna possível, isso quer dizer que deve existir algum tipo de vínculo entre eles. Conforme García (2000, p. 314), Schiller acode essa questão voltando-se para a dialética, já que a única maneira de suprimir uma contraposição é superar completamente os dois elementos enfrentados com um terceiro. Desse modo, a existência de um terceiro impulso que englobe a ambos e que não viole nem a legislação da sensibilidade nem a da razão, é a única maneira de assegurar a unidade harmônica da natureza humana.

Como ponto de intersecção, o terceiro impulso deve obrigatoriamente reunir as características distintas do impulso sensível e formal. Nos termos em que o impulso sensível exige variação, passividade, multiplicidade, tempo e necessidade física, e o impulso formal demanda atividade, unidade, permanência e necessidade moral, o terceiro impulso se caracterizará pela passividade e atividade simultânea, unidade na multiplicidade, suspensão do tempo no tempo e mútua anulação entre a necessidade física e a necessidade moral (GARCÍA, 2000, p. 315). Por ser esse terceiro impulso capaz de ficar a salvo tanto da coação da natureza quanto da constrição da moralidade, Schiller dá-lhe o nome de impulso do jogo ou impulso lúdico.

Enquanto o impulso sensível refere-se à "mera vida", matéria, e o impulso formal tende à razão, à disposição formal e suas relações com a faculdade do pensamento, o objeto do impulso lúdico é a "forma viva". E na medida que a única coisa capaz de suprimir o tempo no tempo, tornar possível a unidade na multiplicidade e anular a contrição física e moral é a beleza, o impulso lúdico não deixa de ser outra coisa que a disposição estética. Mediante essa definição, a beleza aparece aqui não enquanto algo estendido a toda forma viva e encerrada nela, tal qual a estátua contida no mármore, mas como algo passível de impressão, de formação: "somente quando sua forma vive em nossa sensibilidade e sua vida se forma em nosso entendimento o homem é forma viva, e este será sempre o caso quando o julgamos belo" (SCHILLER, 2002, p. 78).

Enquanto consumação da humanidade no homem, a beleza não pode ficar restrita unilateralmente nem à forma, nem à vida, mas ser objeto de ambos os impulsos, ou seja, do impulso lúdico. Dispensado por igual da obediência da razão e da submissão à matéria, o impulso lúdico designa aquilo que não está nem subjetiva nem objetivamente contingente, não constrange o interior nem o exterior. Dessa maneira, coloca-nos em posição de pura contemplação ante o objeto sem despertar em nós nenhum interesse de natureza teórica, prática ou egoísta. Pelo impulso lúdico, o dever não mais constrange e a mente aceita com mais liberdade e calma a realidade das coisas. Para Schiller, somente o jogo torna completa a natureza do homem, tornando a sensibilidade criativa e a razão passiva, fundindo intuição e abstração, ideia e sensação. E essa bela aparência desperta em nós a consciência de uma liberdade que não é somente aquela que nasce da razão, mas flui através da natureza dual do ser humano dando a medida de nossa genuína humanidade: 
Pois, para dizer tudo de uma vez, o homem joga somente quando é homem no pleno sentido da palavra, e somente é homem pleno quando joga. Esta afirmação, que há de parecer paradoxal neste momento, irá ganhar um grande e profundo significado quando chegarmos a relacioná-la à dupla seriedade do dever e do destino; suportará, prometo-vos, o edifício inteiro da arte estética e da mais bem dificultosa arte de viver (SCHILLER, 2002, p. 80).

Com essa definição de impulso lúdico, Schiller radicaliza a ideia de jogo presente na Crítica da faculdade do juízo de Kant, entendendo o impulso lúdico como um jogo entre as capacidades racionais e sensíveis do homem, no qual a ausência de regras ou conceitos identifica-se com a verdadeira liberdade humana. Em primeiro lugar, o homem deve apenas jogar com a beleza, ou seja, sem tentar transformá-la em atividade séria no sentido do impulso formal, não submeter a beleza às leis. Em segundo lugar, Schiller coloca a exigência de que o homem deve jogar apenas com a beleza, isto é, não deve deixar que o jogo distancie-se do ideal de beleza.

Podemos afirmar que as reinvindicações dos outros dois impulsos, formal e sensível, são sérias: enquanto um refere-se à necessidade e à manutenção da vida, o outro diz respeito à realidade das coisas e à preservação da dignidade. Conforme Süssekind (2011b, p. 20), essa pretensa seriedade acarretaria uma objeção quanto à definição do belo como "mero jogo". Com o conceito de impulso lúdico, Schiller inverte o senso comum que sustenta essa objeção que coloca o jogo como limitação, mas que aqui, ao contrário, aparece como ampliação, porque "é o jogo e somente ele que torna completo e desdobra de uma só vez sua natureza dupla". Em outros termos, "com o agradável, com o bem, com a perfeição, o homem é apenas sério; com a beleza, no entanto, ele joga" (SCHILLER, 2002, p. 79).

Para Süssekind (2011b, p. 21), o conceito de impulso lúdico articula-se com a arte sob três pontos principais: 1) o belo artístico seria a convergência entre o impulso formal e o impulso sensível, gestando uma "forma viva" que suspende a oposição entre ambos; 2) o impulso lúdico compreende um determinado juízo sobre a beleza enquanto exigência da razão para a "consumação da humanidade"; 3) o jogo enquanto expressão cultural humana. "Não errará jamais quem buscar o ideal de beleza de um homem pela mesma via em que ele satisfaz seu impulso lúdico" (SCHILLER, 2002, p. 80). Neste ponto, Schiller faz uma série de considerações sobre os jogos ao longo da história, comparando os jogos dos gregos, competições esportivas sem violência, e dos romanos no Coliseu, jogos embasados no derramamento de sangue e na morte. Dessa maneira, Schiller exemplifica como o ideal de beleza de um povo expressa-se no impulso lúdico.

Todavia, Schiller pretende chegar ainda mais longe centrando os seus esforços em tentar demonstrar que somente a beleza torna possível a passagem da sensibilidade para a razão. Em outras palavras, para tornar ao homem sensível racional, o único caminho é antes torná-lo estético. Nessa acepção, a beleza converte-se na chave que torna possível uma transformação subjetiva e objetiva da humanidade, pois abre os caminhos para a educação moral. Segundo Barbosa (2015, p. 232), é na medida em que o gosto contribui para eliminar os obstáculos que impedem a determinação racional da vontade que ele pode vir a ser instrumento da moralidade enquanto seu fundamento externo.

Para Duflo (1999, p. 68), o diagnóstico de Schiller deve ser visto como uma antropologia pragmática que remonta a uma antropologia pura, visto que busca, simultaneamente, o fundamento suprassensível dessa divisão, assim como a possível solução do problema que ela levanta. Desse modo, o ser humano aparece primeiro como um ser da natureza, ou seja, como homem físico ao qual pertence o estado da necessidade em que a natureza age no homem sem o homem. Contudo, o homem só é homem porque não se submete diretamente ao assujeitamento imposto pela natureza e, dessa maneira, ele é, além de homem físico, também homem moral. O indivíduo é inteiramente dividido, marcado por um duplo apego que toma a forma de uma oposição estéril e sem fim, já que se uma dessas legislações esmagasse a outra até fazê-la desaparecer, o que desapareceria seria o próprio homem enquanto tal.

Para terminar essa infeliz oposição do homem consigo mesmo e realizar, no Estado, as mudanças necessárias que podem fazê-lo passar da arbitrariedade à racionalidade sem prejudicar sua natureza sensível, é preciso encontrar um sujeito ou um povo que possua um caráter total, tal qual o possuíam os gregos. A restauração da totalidade não vai ser vista por Schiller na ação política ou tampouco na filosofia, mas na arte. Aqui, conforme Duflo (1999, p. 69), insere-se a antropologia pura 
de Schiller: a partir da humanidade como conceito puro, chega-se ao puro conceito de beleza, aquele que possibilita o retorno à totalidade perdida.

\section{EDUCAÇÃO PELA BELEZA}

É preciso sempre lembrar que o problema de fundo das Cartas parte, de um lado, dos fracassos a que se viu imersa a Revolução Francesa e, de outro, da emergência da Aufklärung. Ainda que os extremos das classes inferiores e superiores levem a sociedade à selvageria e à barbárie, mostrando-a despreparada para o Estado moral, Schiller vai ressaltar a permanência da exigência racional da liberdade e, com ela, a de um sujeito social competente. Contudo, é esse sujeito novo que teima em não surgir e prorroga indefinidamente uma mudança social concreta. Nesses termos, Schiller vai pensar a educação no lastro do Kant de 1783, em "Resposta à pergunta: o que é esclarecimento?” (KANT, 1985). Neste texto, Kant define o esclarecimento (Aufklärung) como a máxima de pensar por si próprio sem a tutela de outro e da heteronomia, o que caracteriza a menoridade (Unmündigkeit). Kant vai desenvolver o conceito de esclarecimento em conexão com o uso público da razão ao colocar o tutor (Vormund) como aquele que fala por alguém, enquanto que o indivíduo emancipado que assume a sua maioridade (Mündigkeit) é aquele que fala publicamente por si mesmo.

Nesses termos, a exigência do esclarecimento converge para uma cultura da razão enraizada na esfera pública. Para Kant, a revolução não poderia efetivar-se e os seus efeitos não passariam do nível superficial, pois dependeriam de uma mudança nos modos de sentir e pensar do povo. Dez anos mais tarde, essa questão vai influenciar Schiller a pensar as dificuldades de alcançar o Estado de liberdade, desautorizando toda a expectativa de mudanças a curto e a médio prazo. Essas considerações também levam Schiller a pensar o contínuo obscurecimento das mentes em uma época de esclarecimento: se a razão purificou os sentimentos e a filosofia, que a princípio separou-se da natureza e que agora a traz de volta, então, questiona Schiller (2002, p. 46), onde reside a causa de ainda sermos bárbaros? O filósofo vai referir-se a Kant para apontar a causa desse estado: Sapere aude! Ousa saber! É preciso disposição de espírito para emancipar-se, tanto que Schiller refere-se à deusa Atena saindo completamente armada da cabeça de Júpiter, pois as suas primeiras ocupações são voltadas para a luta.

Para ser sábio, ousar saber, "é necessário ânimo forte para combater os empecilhos que a inércia da natureza e a covardia do coração opõem à instrução" (SCHILLER, 2002, p. 46). Porém, a cega luta pela sobrevivência, a constante sucessão de penas não deixa aos homens força para uma luta mais árdua contra o erro. Se livres da penosa arte de pensar, entregam de bom grado a outros a tutela de seus conceitos. De outro lado, estão aqueles que, libertos da necessidade, curvam-se à menoridade por sua própria escolha. O ponto central aqui, para Schiller, é debater como uma educação só para o material, o físico, e outra voltada unicamente para a racionalidade não são capazes de tirar o indivíduo de seu torpor e incentivá-lo a emancipar-se. Conforme Schiller: (2002, p. 47) "toda a ilustração do entendimento só merece respeito quando reflui sobre o caráter, pois o caminho para o intelecto precisa ser aberto pelo coração". Logo, a formação que vise à emancipação deve, obrigatoriamente, tomar para si a tarefa de educar a sensibilidade.

Para Schiller, não há projeto educativo sem a crença de um progresso tanto do indivíduo quanto da sociedade. Logo, se tal progresso é possível é porque a natureza humana não se resume ao eterno antagonismo entre razão e sensibilidade, mas tem como marca o desenvolvimento harmônico das suas faculdades enquanto ideal de humanidade. Enquanto o belo torna possível a passagem do racional para o sensível, levando unidade à natureza humana, Schiller concentra as possibilidades de transformação na educação para a beleza. Não é à toa que o autor (SCHILLER, 2002, p. 28-29), vai colocar a educação estética no status de uma arte em que o educador é o artista-pedagogo, distinguindo-o do artista mecânico e do artista do belo.

O artista mecânico ${ }^{5}$ toma o material amorfo em suas mãos para dar-lhe uma forma que satisfaça aos seus fins, sem se importar com o fato de impingir-lhe violência, "pois a natureza que ele elabora não merece por si respeito algum, ele não quer o todo pelas partes, mas apenas as partes pelo

5 Aqui a arte tem o sentido de técnica (technê) ou artifício.

Educação em Revista|Belo Horizonte|v.36|e20089|2020 
todo" (Schiller, 2002, p.28). Por sua vez, o artista do belo toma o mesmo material e transforma-o pela violência, embora evite mostrá-la, ou seja, não respeita a matéria, mas procurará, "por uma aparente deferência para com ela, iludir o olho que protege a liberdade da mesma" (SCHILLER, 2002, p.29). A situação vai ser completamente diferente, segundo Schiller, quando se trata do artista pedagogo ou político que toma o homem como seu material e sua tarefa ao mesmo tempo. "Aqui o fim retorna à matéria, e é somente porque o todo serve às partes que as partes devem submeter-se ao todo" (SCHILLER, 2002, p.29). O respeito à matéria que tem o artista político é muito diverso do que tem o artista mecânico e o artista do belo: ele deve aproximar-se da sua matéria cuidando de sua especificidade e personalidade não apenas nos termos subjetivos, como poderia fazer o artista do belo, mas objetivamente e para a essência interna.

Essa noção do educador como artista político reflete diretamente na educação como meio que conduz à sociedade. Para Schiller, o Estado deve formar-se por si e para si, de maneira que é somente quando as suas partes afinam-se com a ideia do todo que ele pode tornar-se real. $\mathrm{Na}$ medida em que o Estado representa a humanidade em termos coletivos, ele deve observar no que concerne aos cidadãos a mesma relação que eles têm para consigo mesmos e "só poderá honrar a humanidade subjetiva no mesmo grau em que ela estiver elevada à humanidade objetiva" (2002, p. 29).Nesses termos, Schiller vai afirmar que se a formação dos sujeitos resulta numa determinada concepção de Estado como reunião desses indivíduos, o caráter que se dará à educação do povo vai definir a própria ideia de humanidade:

Se o homem interior é uno consigo, ele salva sua especificidade mesmo na mais alta universalização de seu comportamento, e o Estado será apenas o interprete de seu belo instinto, a formula mais nítida de sua legislação interna. Se, por outro lado, no caráter de um povo o homem subjetivo se opõe ainda contraditoriamente ao objetivo que apenas a opressão do primeiro permita a vitória do segundo, o Estado empunhará contra o cidadão o severo rigor da lei e deverá, para não ser sua vítima, espezinhar sem consideração uma individualidade tão hostil (SCHILLER, 2002, p. 29).

Daí a importância que Schiller atribui à educação estética como meio que permite a passagem do Estado sensível e material para o Estado formal e moral. A beleza permite ultrapassar o Estado sensível, alcançar o Estado estético pelo domínio racional das pulsões e, com isso, chegar ao Estado político, garantia da autonomia assim adquirida (JIMENEZ, 1999, p. 159). Se a liberdade política é a meta mais elevada, na qual devem estar postos todos os esforços da cultura, se nela consuma-se a grande obra que a Revolução não soube criar, então a tarefa política torna-se essencialmente tarefa pedagógica, formativa, pois, para Schiller, é preciso criar o cidadão para a constituição antes de pedir que as pessoas submetam-se a uma constituição. Contudo, não haverá aqui um círculo ${ }^{6}$ ? Schiller não o nega, mas ao mesmo tempo aponta o modo de evitá-lo: deve-se agir sobre o caráter dos homens prescindindo do recurso ao Estado. Para tanto, é preciso encontrar um elemento que se conserve puro apesar de toda corrupção política: as belas artes (SCHILLER, 2002, p. 49).

Mas será mesmo a arte um elemento puro? E, quanto à influência do meio, da época em que escreve o autor, e o que não dizer de sua classe social? Schiller adverte, "o artista é, decerto, o filho de sua época, mas ai dele se for também seu discípulo ou até seu favorito" (2002, p. 50). Aparece aqui a temática do classicismo com a qual os pensadores alemães estavam ocupados. É legítimo que o artista volte-se para a rica cultura grega, absorva a clareza daqueles tempos para voltar ao seu século com o fim de purificá-lo. Assim, ele vai extrair de tempos mais nobres a essência imutável e absoluta para além do tempo. Esta não deixa de ser outra coisa que a forma estética, conceito central, mais tarde, na filosofia de Marcuse: "é dali, do puro éter de sua natureza demoníaca, que jorra a fonte da beleza, intocada pela corrupção das gerações e dos tempos que, muito abaixo dali, agitam-se em redemoinhos

\footnotetext{
${ }^{6}$ Fichte já havia apontado no ensaio Über Geist und Buchstabe in der Philosophie: In einer Reihe von Briefe, sobre o problema do círculo que envolve a estética e a política nas Cartas, mas recusado por Schiller na publicação de sua Horen. Segundo Fichte, as épocas de servidão são, ao mesmo tempo, as de falta de gosto estético. Nesses termos, se não é aconselhável deixar os homens livres antes que desenvolvam seu senso estético, é impossível desenvolvê-lo antes que sejam livres. A ideia de elevar o homem à liberdade pela educação estética põe-nos em um círculo se antes não for encontrado uma maneira de despertar nas massas a capacidade e a coragem de não serem escravos de ninguém (SCHILLER, 2002, 144, nota 06 do tradutor).

Educação em Revista|Belo Horizonte|v.36|e20089|2020
} 
turvos" (SCHILLER, 2002, p. 50). Ainda que a humanidade esteja corrompida, a arte manteve salvo o Ideal e a verdade com a qual é possível projetar novas formas de existência: "da cópia será refeita a imagem ideal".

O belo tem o caráter de unir as duas naturezas antagônicas do sujeito para torná-lo um todo harmonioso: "pela beleza, o homem sensível é conduzido à forma e ao pensamento; pela beleza, o homem espiritual é reconduzido à matéria e entregue de volta ao mundo sensível" (SCHILLER, 2002, p. 91). A formação do caráter dá-se, portanto, pela via da retificação dos conceitos, assim como pela purificação dos sentimentos, sendo que um caráter perfeito é aquele no qual ambos os impulsos atuam em equilíbrio, materializando-se através do impulso lúdico. Conforme Süssekind (2001a, p.17), esse estado depende de uma mobilização da cultura enquanto mobilização integral das esferas de validade da razão, o que implica uma radicalização da Aufklärung: um conceito uno de racionalidade. Logo, a tarefa da cultura estética será desencadear esse processo assegurando a harmonia dos impulsos.

A natureza fornece prodigamente ao indivíduo a disposição a esse livre e gratuito dispêndio de energia que é o jogo; inculca-lhe o gosto pelo adorno e, enquanto o separa da mera materialidade, refina os seus sentimentos no cultivo da racionalidade, convertendo-o, através da cultura e da arte, em uma criatura estética. A beleza, conforme Schiller, é nossa segunda criadora, já que se encarrega de continuar o trabalho da natureza, gerando um estado de ânimo que contém em si a totalidade do humano e que, agora, sim, é responsável por levar o homem à sua completa realização. Certamente, a disposição estética por si só não melhora moralmente o homem nem amplia os seus conhecimentos, mas lhe devolve a "liberdade de ser o que deve ser", outorgando-lhe a "suprema de todas as dádivas, a dádiva da humanidade" (SCHILLER, 2002, p.106).

Enquanto favorece todos os âmbitos da humanidade, a estética conduz ao desenvolvimento completo, universal. Todos os outros exercícios impõem e desenvolvem uma aptidão particular; somente a estética conduz ao ilimitado. A experiência estética é, para Schiller, o modelo de reconciliação e desenvolvimento pleno das faculdades do homem em conexão direta com a ação política, já que coloca, como objetivo, a transformação do mundo pela transformação individual. $\mathrm{Na}$ medida em que a beleza transforma o mundo oferecendo ao indivíduo a aparência de liberdade, essa aparência transforma o seu interior, restabelecendo o equilíbrio de sua natureza. Dessa maneira, se o homem consegue tornar realidade esse equilíbrio interior, não encontrará obstáculo para converter em realidade fora de si o que somente como aparência mostrava-lhe a beleza.

O estado estético conduz ao homem nobre, não apenas em sentido próprio, mas sobretudo porque é capaz de modificar a realidade que está a sua volta. Para Schiller, o espírito não se basta em ser livre, ele também tem necessidade de libertar tudo o mais à sua volta, mesmo o inerte. Assim, a beleza aparece como "única expressão possível da liberdade no fenômeno" (SCHILLER, 2002, p. 116, nota do autor). Visto sob essa perspectiva, o homem em sentido pleno, o homem lúdico, não busca somente evadir da prisão de sua moralidade, mas se empenha também em dar vida a tudo o que o cerca, em libertar os objetos que habitam a sua sensibilidade, tornando possível o cultivo maior desta.

Schiller (2002, p. 106) vai dizer que, no estado estético, “o homem é zero" se considerada a total ausência de determinação particular nele, tanto do âmbito formal quanto sensível. Logo, o belo é de todo indiferente ao conhecimento e à intenção moral, pois a beleza não oferece resultados isolados nem para o entendimento nem para a vontade e não auxilia sequer no cumprimento de um dever: "é, numa palavra, tão incapaz de fundar o caráter quanto de iluminar a mente" (SCHILLER, 2002, p.106). Pela cultura estética, permanecem indeterminados o valor e a dignidade pessoais de um indivíduo e, na medida em que eles só podem aparecer como dependentes dele mesmo, essa perspectiva deixa em aberto a possibilidade do homem, pela natureza, fazer o que quiser de si mesmo, ou seja, pela estética é completamente devolvida ao homem "a liberdade de ser o que deve ser". A estética, em sua ausência total de determinabilidade, possibilita uma liberdade que havia sido tolhida pela coerção da natureza na sensação e pela legislação da razão no pensamento.

Se, por um lado, a disposição estética é a ausência total de determinabilidade em termos individuais, por outro lado, ela deve ser vista como um estado de máxima realidade quando se refere à soma de forças que, nela, estão conjuntamente ativas, pois não se pode esquecer que esse estado estético reúne em si as disposições sensível e formal, suprimindo a contingência de ambas. A estética 
favorece a todas as disposições justamente por ser condição da possibilidade de todas elas. "Todos os outros exercícios dão à mente uma aptidão particular e impõe-lhe, por isso, um limite particular; somente a estética conduz ao ilimitado" (SCHILLER, 2002, p. 109). Para Schiller, somente o estado estético é um todo em si mesmo, no qual somos arrancados do tempo e entregues à nossa humanidade.

Ao entregarmo-nos à fruição estética da beleza autêntica, somos levados, a um só tempo, da seriedade ao jogo, do movimento ao repouso, do pensamento abstrato para a intuição. Dirá Schiller que a autêntica obra de arte deve levar-nos a uma disposição para a alta serenidade e liberdade de espírito combinada com a força e a energia. Não há nessa disposição, que nos deixa em contato com a obra, pedra de toque mais segura da verdadeira qualidade estética. Essa experiência transforma-nos nos termos em que faz nascer em nós uma disposição que reflui sobre o nosso caráter e que ultrapassa o âmbito meramente estético. Schiller (2002, p. 110) sustenta que "se após uma fruição desta espécie achamo-nos dispostos de preferência a algumas maneiras de sentir ou agir, mais inaptos e enfastiados para outras, isso serve como prova inconteste de que não experimentamos um efeito puramente estético".

$\mathrm{Na}$ medida em que avança, o impulso lúdico vai acrescentando abundância estética à necessidade, até que se desprende por completo das amarras da privação e a beleza torna-se, por si mesma, objeto de seu empenho. Só então, em meio ao terrível reino da força e ao sagrado reino das leis, o impulso lúdico pode, enfim, erguer imperceptivelmente "um terceiro reino, alegre, de jogo e aparência, em que desprende o homem de todas as amarras das circunstâncias, libertando-o de toda coerção moral ou física" (SCHILLER, 2002, p.139). Neste sentido, acontece a transformação do estado de coisas, pois o estado estético executa a vontade do todo mediante a natureza do indivíduo.

\section{A ATUALIDADE DA EDUCAÇÃO ESTÉTICA SCHILLERIANA}

Vendo-as como parte da história da filosofia, as Cartas sobre a educação estética do homem, de Schiller, possuem um lugar fundador na história do conceito de jogo. Mesmo que Pascal abra um amplo espaço para a ideia de jogo, ou que Kant coloque essa noção como parte importante das questões da Crítica da faculdade do juíro, para Duflo (1999, p. 65), o caráter iniciador do pensamento de Schiller permanece inegável, sendo determinante em duas consequências mais imediatas. Primeiro, Schiller marca uma virada após a qual o pensamento sobre o jogo será possível e legítimo pela importância filosófica demonstrada por essa temática. E, segundo, todo o discurso posterior sobre o jogo deverá situar-se em relação a esse início, ou seja, de certa forma, ainda vivemos a herança de Schiller. A noção de jogo ao longo da história da filosofia tem vocação intrínseca para nomear um ponto de encontro entre duas naturezas divergentes, o racional e o sensível. A filosofia de Schiller vai assumir totalmente e levar a um grau até então inigualável a capacidade do jogo para descrever um ponto de unificação possível, processo que se desenrola pela educação estética.

A educação estética aparece, dessa forma, como uma composição reflexiva que vê o homem como organismo vivo em constante transformação em seu compromisso com a prática política. Pelo harmônico funcionamento da natureza interna do indivíduo chega-se ao melhoramento e transformação objetiva do estado de coisas existente. De fato, a fragmentação pela qual se viu envolvido o homem no auge da Revolução levou Schiller a pensar a ideia de uma formação total, no sentido de que a natureza, que tudo une, dê forma ao sujeito, e não o entendimento, que tudo separa. E embora as Cartas sejam escritas em uma época bastante distante temporalmente da nossa, a crítica schilleriana soa-nos hoje estranhamente familiar:

Eternamente acorrentado a um pequeno fragmento do todo, o homem só pode formar-se enquanto fragmento; ouvindo eternamente o mesmo ruído monótono da roda que ele aciona, não desenvolve a harmonia do seu ser e, em lugar de imprimir a humanidade em sua natureza, torna-se mera reprodução de sua ocupação, de sua ciência (SCHILLER, 2002, p. 37).

De fato, Schiller aqui não denuncia meramente o utilitarismo da época, mas o mecanismo frio de organização social que submete os indivíduos a um injusto princípio de rendimento econômico, com todas as suas consequências. Não há como negar que, em nossa época, o utilitarismo criticado por Schiller aparece sob formas muito mais agravadas. A fragmentação do indivíduo atrelada 
ao alto grau de desenvolvimento tecnológico alcança dimensões profundas da natureza humana, imprimindo, na própria subjetividade individual, o seu modus operandi. Para Marcuse (2001), a tecnologia não diz respeito apenas a um modo de produção ou desenvolvimento de determinada sociedade; ela também projeta, a partir de uma estrutura apriorística, um determinado modo de vida e de relacionamento com o todo. Isso na medida em que ela atinge a estrutura pulsional, projetando, a partir da própria subjetividade dos sujeitos, um parâmetro próprio de ação e, em certo sentido, uma forma de sociabilidade.

Como ressalta Dalbosco (2014, p. 1031), na modernidade, a tecnificação da ciência e a ênfase ao aspecto metódico-experimental vinculam a noção de experiência humana a um princípio quantificacionista. Ao proceder dessa maneira, a ciência moderna legitima os modos dogmáticos de experiência, levando ao extremo uma importância exagerada dada ao impulso formal, em um diagnóstico já mostrado por Schiller em relação ao alvorecer da modernidade. Em sua versão positivista, a ênfase recai sobre um conceito de razão absolutizado e dogmático, estabelecendo um monopólio metodológico que exclui ou enfraquece outras formas de acesso ao conhecimento e de compreensão do mundo, como é o caso da estética.

Todavia, levando-se em conta a dialética da razão moderna, é preciso reconhecer a forte influência do projeto educacional iluminista e o seu posicionamento epistemológico de crença na razão como fonte de emancipação. O progresso pela razão, levando pela via do conhecimento a um avanço em termos de humanização, aparece como uma das tarefas centrais da educação na modernidade. Entretanto, nas palavras de Goergen (2005, p. 60), esse ideário tende a partir de uma visão da escola como instituição universalizadora e que promove ideais unificadores. Por conseguinte, não deixa de sublinhar ou pautar grande parte de sua conduta em dimensões uniformizadas da cultura dominante, desconsiderando aspectos importantes como a historicidade e a contingencialidade da experiência formativa e mesmo os potenciais formativo-emancipadores contidos em uma racionalidade estética. Expresso em outros termos, nesse caso, a razão torna-se instrumentalizada e instrumentalizadora e, como tal, coloca-se não mais como porta de acesso à emancipação, mas como veículo de manutenção da ordem vigente.

É através de Schiller que, pela primeira vez, encontramos um questionamento consistente acerca da rigidez da prevalência do âmbito formal enquanto fundamento de uma ordem racional universal. Essa reflexão induz a repensarmos a posição do âmbito sensível no processo educativo enquanto parte essencial da ideia de formação. Conforme Hermann (2005, p. 75), o momento estético quebra com a rigidez da aplicação de princípios em favor dos aspectos contingentes da vida humana, na qual se ressalta a necessidade do gosto para o âmbito moral, ou seja, o elemento estético oferece uma perspectiva formativa que a razão mesma, reduzida a sua dimensão cognitiva, não é capaz de produzir.

Com o tratamento do belo e da problematização da educação estética pela via do impulso lúdico, Schiller traz tematizações importantes para o âmbito da formação. Conforme Lago (2014, p.58), na medida em que o pensador ousou tratar da questão da fragmentação do indivíduo, propondo a sua superação no equilíbrio entre impulso formal e sensível pela via do impulso lúdico, pode colocar em cheque a pretensa prevalência da razão como modelo de formação. Com efeito, o jogo liberta-se das faculdades do entendimento, conforme entendia Kant, para situar-se enquanto elemento central da formação, em que o homem alcança sua total plenitude.

Embora a ênfase de Schiller na beleza como via unificadora entre racionalidade e sensibilidade possa, em um primeiro momento, fundamentar um conceito perigoso de cultura (tendo em vista, principalmente, o direcionamento posterior do belo no contexto dos Estados totalitários), é preciso considerar que o autor tem em mente aqui a constituição harmoniosa do indivíduo cindido, para o qual as exigências do impulso formal e do sensível levam ao desequilíbrio. O belo constitui-se em um princípio formativo que possibilita o nascimento de um homem emancipado que reúne condições de viver a completude do seu ser. Com efeito, o estado lúdico tem a função de, ainda que ambos sejam levados à máxima expressão, limitar tanto o sentimento quanto a razão sem impor-se pela violência: no impulso lúdico, neste aspecto, Schiller argumenta: "as duas legislações devem existir com plena independência, e ainda assim perfeitamente unidas” (2002, p. 124). A beleza cumpre a função de ligar o conhecimento sensível ao racional, pois como obra da livre contemplação, com ela é possível 
penetrar no mundo das Ideias sem abandonar o mundo sensível. Ao limitar os excessos de ambos os impulsos, a beleza torna-se instrumento de mediação entre os sentidos e a razão e faz nascer o estado lúdico que guia o homem em uma formação emancipatória.

Ainda que o artista mecânico possa interromper o funcionamento do objeto, tornando-o imóvel para imprimir-lhe a forma sensível e agir sobre ele, esse procedimento não pode ser adotado quando o assunto é a formação humana. Enquanto o artesão que conserta o mecanismo do relógio permite que a corda acabe-se para melhor trabalhar nele, o mecanismo vivo da formação humana "precisa ser corrigido enquanto pulsa, as engrenagens são trocadas enquanto giram" (SCHILLER, 2002, p. 25). Para tanto, o impulso lúdico fornece ao artista-pedagogo o mecanismo que lhe possibilita operar a transformação no movimento incessante do Estado. É na dinâmica social que o homem forma-se enquanto indivíduo e membro da sociedade. Contudo, essa formação demanda cuidado, já que se deve evitar os extremos de recair tanto na abstração do racionalismo vazio, quanto na mera materialidade da sensação. Nestes termos, Schiller coloca a necessidade de a formação ser mediada pelo impulso lúdico, de maneira que o indivíduo não fique restrito ao informe, mera impressão da vida, mas possa tornar-se forma viva, ou seja, quando a sua forma vive em sua sensibilidade e sua vida forma-se em seu entendimento.

Podemos pensar aqui o sentido educativo do impulso lúdico sinalizado por Schiller como uma dinâmica na qual não cabe a imposição mecânica da forma sobre o objeto, mas a valorização da experiência entre os sujeitos envolvidos como responsáveis pelos processos formativos enquanto dialética entre o formal e o sensível. Trata-se, sobretudo, de superar a educação como um processo de imposição do conhecimento, como ocorre na tarefa do artista mecânico que age sobre o objeto, passando-se a concebê-la como uma dinâmica política-pedagógica de ação dialética entre sujeitos profundamente envolvidos em seu processo. A pedagogia em seu sentido tradicional não deixa de ser resultado da rejeição dessa dinâmica que exige a entrega dos envolvidos, ademais de ressaltar a distância entre razão e sensibilidade. Somente o artista-pedagogo é capaz de fazer surgir a forma viva, o espaço por excelência da formação em seu sentido integral.

Schiller, com o conceito de impulso lúdico, põe ênfase em um ideal de formação que coloca o ser humano como ser que só pode atingir a sua completude no equilíbrio perfeito, percorrendo um caminho em três níveis: o físico, o estético e o moral. Se, no primeiro, a sujeição à natureza é total, mas também é via de acesso ao mundo pelos sentidos, no nível da contemplação estética, ocorre uma mediação que torna possível a sua transição do estado físico ao moral. A educação estética schilleriana coloca a tarefa de repensar nossos processos formativos no equilíbrio entre sensibilidade e razão, evitando os extremos, tanto de uma abordagem puramente teórica quanto a que preconiza unicamente a empiria. O racional e o sensível, em sentido schilleriano, devem ser tomados como âmbitos constitutivos de uma ideia de formação integral, que veja o ser humano em sua totalidade, o que possibilitaria, por conseguinte, pensar também a transformação da realidade em que se inserem os processos educativos.

\section{CONSIDERAÇÕES FINAIS}

Considerando-se a totalidade das Cartas, é-nos impossível negar a sua ingente atualidade, sobretudo, quando elas são relidas dentro de um contexto histórico de enfraquecimento das artes e da cultura, de desvalorização do papel formativo da sensibilidade, de obscurantismo e de proliferação de formas sofisticadas de reificação e da fragmentação do humano. Afinal, a schilleriana "tarefa para mais de um século" continua aberta. A fragmentação a que se referia o autor certamente continua mais presente hoje que em qualquer outra época, sendo agravada pelo constante embate entre o progresso quantitativo e as necessidades qualitativas que resultam na prevalência do aspecto instrumental que perpassa muitos dos processos sociais e educativos na atualidade. Quando assim orientada, a educação transforma-se em mero ensino técnico-profissionalizante, apropriação de habilidades e competências orientada pelo investimento individual em capital humano reduzido à busca de empregabilidade e renda.

Contudo, para Schiller, a exigência de uma cultura integral passa obrigatoriamente pela valorização, em igual medida, tanto do impulso formal quanto do impulso sensível, de maneira que 
ambos formem parte ativa de um conceito mais amplo de racionalidade. Nestes termos, a educação estética significa a superação tanto da ênfase no intelectualismo, enquanto expressão unilateral da cultura, quanto do cognitivismo pedagógico, enquanto modo reducionista de compreender os processos educativos. Neste sentido, a harmonização dos impulsos opostos, o sensível e o formal, através do impulso lúdico e do belo, permitiria um uso aprimorado das faculdades humanas. $\mathrm{O}$ ser humano quando em condições de equilibrar tais impulsos é um homem sábio moralmente, livre politicamente e integral em termos formativos.

Cabe conceber, portanto, a educação estética schilleriana como empenhada em recuperar os aspectos críticos e emancipatórios da arte enquanto parte do esforço de formação do humano e de delineamento de um conceito ampliado de racionalidade. Ao abrir espaço para a mediação entre o homem e a natureza sensível por meio da arte, Schiller apresenta uma educação estética comprometida com a emancipação, colocando o foco nos potenciais formativos da arte e do gosto. Na medida em que condiciona o impulso lúdico, a beleza traduz o sentido mais pleno do humano, sua forma viva. Por essa razão, concluímos dando razão a Schiller sobre o privilegiado lugar da beleza na formação do humano: "enquanto apenas meditamos sobre sua forma, ela é inerte, mera abstração; enquanto apenas sentimos sua vida, esta é informe, mera impressão. Somente quando sua forma vive em nossa sensibilidade e sua vida se forma em nosso entendimento o homem é forma viva (...)" (SCHILLER, 2002, p.78).

\section{REFERÊNCIAS}

BARBOSA, R. Schiller e a cultura estética. Rio de Janeiro: Zahar, 2004. 42 p. (Coleção Passo-apasso, 42).

BARBOSA, R. Educação estética e educação sentimental: um estudo sobre Schiller. ArteFilosofia, Ouro Preto, n.17, p. 146-169, Dezembro, 2014.

BARBOSA, R. A especificidade do estético e a razão prática em Schiller. Kriterion, Belo Horizonte, n. 112, p. 229-242, Dezembro 2015.

DALBOSCO, C. A. Pesquisa educacional e experiência humana na perspectiva hermenêutica.

Cadernos de Pesquisa, v.44, n.154, p.1028-1051, out./dez. 2014.

DUFLO, C. O jogo: de Pascal a Schiller. Porto Alegre: Artmed, 1999. 88 p.

FICHTE, J. G. Sobre o espírito e a letra na filosofia. Tradução de Ulisses Razzante Vaccari. São Paulo: Humanitas/Imprensa Oficial do Estado de São Paulo, 2015. 348 p.

GARCÍA, J. A la libertad por la belleza: la propuesta filosófica de F. Schiller. Madrid: Universidad Nacional de Educación a Distancia, 2000. 408 p.

GOERGEN, P. Pós-modernidade, ética e educação. $2^{a}$ edição. Campinas: Autores Associados, 2005. 95 p.

HABERMAS, J. El discurso filosófico de la modernidad: doce lecciones. Madrid: Taurus, 1993. 461 p.

HERMANN, N. Ética e estética: a relação quase esquecida. Porto Alegre: EDIPUCRS, 2005. 84 p.

JIMENEZ, M. O que estética? Trad. Fulvia M. L. Moretto. São Leopoldo: Ed. UNISINOS, 1999. 413 p. 
KANT, I. Resposta à pergunta: que é esclarecimento? In: KANT, I. Textos Seletos. $2^{\mathrm{a}}$ ed. Petrópolis: Vozes, 1985. 112 p.

KANT, I. Crítica da Faculdade do juízo. Tradução de Valerio Rohden e Antônio Marques. 1 ed. Rio de Janeiro: Forense Universitária, 1995. 390 p.

LAGO, C. Experiência estética e educação: articulação a partir de Hans-Goerg Gadamer. Porto Alegre: EDIPUCRS, 2014. 164 p.

MARCUSE, H Algunos comentarios sobre Aragón: el arte y la política en la Era Totalitaria. In: MARCUSE, H. Guerra, tecnología y fascismo: textos inéditos. Fundação Editora da UNESP; Editorial Universidad de Antioquia: Medellín, 2001, p. 242-259.

SCHILLER, F. SCHILLER, Friedrich. Kallias. In: . Kallias; Cartas sobre la educación estética del hombre. Traducción y notas Jaime Feijóo y Jorge Seca. Ed. Bilingüe. Anthropos: Barcelona, 1999.

A educação estética do homem numa série de cartas. 4 ed. Trad. Roberto Schwarz e Márcio Suzuki. Introdução e notas Márcio Suzuki. São Paulo: Iluminuras, 2002. 123 p.

SÜSSEKIND, P. Schiller e o desafio de pensar a modernidade. In: HUSSAK, P.; VIEIRA, V.

Educação estética: de Schiller a Marcuse. Rio de Janeiro: NAU: EDUR, 2011a.

SÜSSEKIND, P. O impulso lúdico: sobre a questão antropológica em Schiller. Arte filosofia, Ouro Preto, n.10, p. 11-24, abr. 2011b.

Submetido: 15/04/2020

Aprovado: 11/09/2020 